\title{
Return on Scientific Investment - RoSI: a PMO dynamical index proposal for scientific projects performance evaluation and management
}

\author{
Retorno sobre o Investimento Científico - RoSI: uma proposta de índice dinâmico PMO \\ para avaliação de desempenho e gestão de projetos científicos
}

\author{
Cristofer André Caous ${ }^{1}$, Birajara Machado¹, Cora Hors², Andrea Kaufmann Zeh³,
} Cleber Gustavo Dias ${ }^{2}$, Edson Amaro Junior ${ }^{4}$

\begin{abstract}
Objective: To propose a measure (index) of expected risks to evaluate and follow up the performance analysis of research projects involving financial and adequate structure parameters for its development. Methods: A ranking of acceptable results regarding research projects with complex variables was used as an index to gauge a project performance. In order to implement this method the ulcer index as the basic model to accommodate the following variables was applied: costs, high impact publication, fund raising, and patent registry. The proposed structured analysis, named here as RoSI (Return on Scientific Investment) comprises a pipeline of analysis to characterize the risk based on a modeling tool that comprises multiple variables interacting in semi-quantitatively environments. Results: This method was tested with data from three different projects in our Institution (projects $A, B$ and $C$ ). Different curves reflected the ulcer indexes identifying the project that may have a minor risk (project C) related to development and expected results according to initial or full investment. Conclusion: The results showed that this model contributes significantly to the analysis of risk and planning as well as to the definition of necessary investments that consider contingency actions with benefits to the different stakeholders: the investor or donor, the project manager and the researchers.
\end{abstract}

Keywords: Research and development projects; Research financing; Investments/economics; Innovation; Biomedical technology

\section{RESUMO}

Objetivos: Propor um novo índice adaptado de riscos esperados para avaliar, planejar e acompanhar projetos de pesquisa que dependem de financiamento e estrutura adequada para 0 seu desenvolvimento. Métodos: Uma grade de resultados aceitáveis em relação aos projetos de pesquisa com variáveis complexas foi aplicada como índice para mensurar 0 desempenho dos projetos. Para sua implementação foram utilizados 0 índice de ulcer como medida básica para acomodar as seguintes variáveis: custos, fator de impacto de publicação, levantamento de fundos e registro de patentes. Obteve-se uma ferramenta de modelagem aqui denominada "Retorno sobre Investimento Científico" (RoSI) que permitiu mensurar e acompanhar projetos de modo analítico, levando-se em conta o conjunto dos resultados esperados, as respectivas variáveis e suas interações analisadas num ambiente virtual semi-quantitativo. Resultados: 0 modelo foi testado para avaliação de três projetos da Instituição (projetos $A, B, e C$ ). Diferentes curvas refletem os índices de ulcer identificando o projeto de menor risco (projeto C) relacionado ao desenvolvimento e resultados esperados de acordo com 0 investimento inicial ou total considerado. Conclusão: 0 modelo contribuiu tanto para a quantificação dos riscos e planejamento, quanto para a definição de investimentos necessários que contemplem ações de contingência, beneficiando os diferentes stakeholders envolvidos: 0 financiador (investidor ou doador), o gestor e os pesquisadores.

Descritores: Projetos de pesquisa e desenvolvimento; Financiamento da pesquisa; Investimentos em saúde/economia; Inovação; Tecnologia biomédica

Study carried out at Instituto do Cérebro - InCe, Hospital Israelita Albert Einstein - HIAE, São Paulo (SP), Brazil.

${ }^{1}$ Instituto do Cérebro - InCe, Hospital Israelita Albert Einstein - HIAE, São Paulo (SP), Brazil.

2 Instituto Israelita de Ensino e Pesquisa Albert Einstein, Hospital Israelita Albert Einstein - HIAE, São Paulo (SP), Brazil.

${ }^{3}$ HCK - Projetos e Pesquisas, São Paulo (SP), Brazil.

${ }^{4}$ Department of Diagnostic Imaging and Instituto do Cérebro - InCe, Hospital Israelita Albert Einstein - HIAE, São Paulo (SP), Brazil.

Corresponding author: Cristofer André Caous - Avenida Albert Einstein, 627/701, Instituto do Cérebro - Morumbi - Zip code: $05651-901$ - São Paulo (SP), Brazil - Phone: (55 11) 2151-0941 -

E-mail: cacaous@gmail.com

Received on: Sep 9, 2011 - Accepted on: May 16, 2012

Conflict of interest: none. 


\section{INTRODUCTION}

Science outcomes can be described by creation, discovery, experimentation, reorganization and knowledge dissemination related to physics, biology and social natures ${ }^{(1)}$. In a contextualized manner it deals with the study of nature and its characteristics of phenomena: the universe physiology - from a single cell to an organized and intricate system ${ }^{(2)}$. According to the disciplinary field or area of knowledge the main outcomes are classified and validated by their peers (published scientific articles), methodology and accessibility (as software, for example). In order to understand this complex role played by science and society few concepts have to be considered when planning a structured risk analysis. In the following paragraphs we provide the basis of our motivation to the work presented herein.

Science - as a whole - is modulated by many determinants: new technologies, inventions and innovations. The current methods to evaluate science - scientometrics research - are aimed at qualifying and/or quantifying science impacts on human society. It is based on logic and data mining (economical indexes are rarely used). In general, it adapts certain variables linked with past performance obtained from scientists or their research group recordings with the aim of evaluating the risk of new research proposals. This process is, by far, susceptible to failure. In fact, not all relevant discoveries are made by well-established research groups. On the contrary, the innovation process often is a result of new concepts and questions raised in other environments. Paradoxically, new ideas in science usually are not necessarily easier to find in well-established research groups. Technology is a better contained concept, it can be defined as a process designed to convert information in novel products. Additionally, it comprehends every single instrument, technique, product or proceeding, equipment or method to build or assemble and increase human capacity ${ }^{(3)}$. So, technology is not necessarily the science application but rather, a consequence of it. Almost all technological outcomes or products are much better defined and well established: patents, royalties and process applications are part of our society. However, the invention potential is evaluated in terms of patentability requirements - not always easy to quantify. These requirements are defined as innovation, inventive stage and industrial applicability. Therefore, any form of invention ought to convene these requirements in order to get a legitimate patent. It is essential to point out that the patent system is the finest manner to protect technological developments in every country or region.
Patent applications and granted patents have increased throughout the last 15 years, ever since companies and universities became aware of the importance of preserving commercial rights purposes promoting newfangled business opportunities (Figure 1).

Although there is a clear link between scientific developments and technology production, a practical connection is not trivial. Thus, measures of technological achievements are not directly applied to the scientific processes. An invention is the creation of a new technology, a novel methodology to realize a nonobvious function for someone with high qualification skills in a determined professional field ${ }^{(4)}$. So, a bright new technology reaches a determined objective or task when an original or innovative principle is applied ${ }^{(5)}$. The concept of research and development is combined by a set of scientific and technological activities to produce a state-of-the-art knowledge. Also, to build up modern techniques established on a previous principle or proficiency(6). On the other hand, the scientific process is rather complex: it comprehends events from the original question - in fact the critical starting point is a well-posed scientific question - to the final answers.

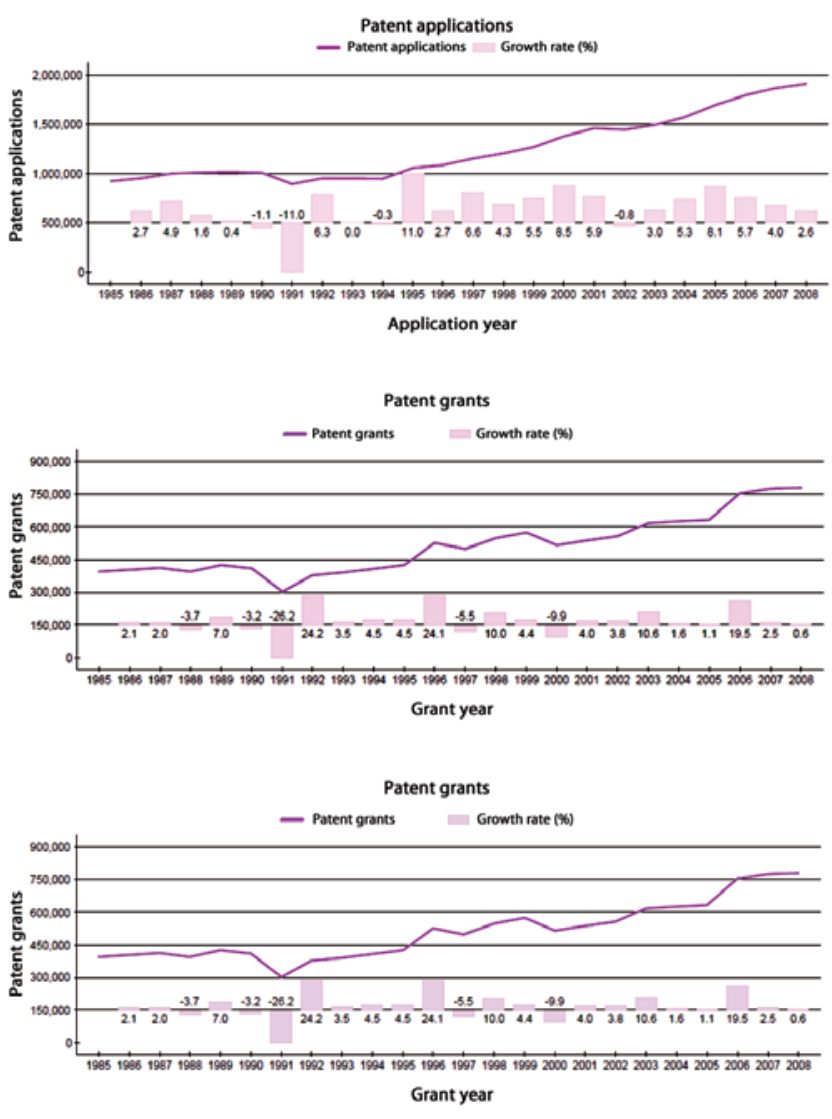

Figure 1. The graphics show patent applications and patent grants within the past 24 years depicting the global intellectual property indicators percentage of growth. Source: WIPO - http://www.wipo.int/ipstats/en/wipi/ 
The translation of the "final research answers" into a product or process applicable in the human society defines the necessary further steps in the production pipeline.

An interesting example is to place neuroscience in an imaginary timeline as a landmark. The scientific process has evolved from "self-sufficient laboratories" to multi disciplinary platforms. We arguably may suggest the 1970's as the turning point period. Despite primitive experiments made by the Egyptian culture, neuroscience developed together with human legacy across the centuries. At the beginning the main concern comprised the cellular morphology with Rámon \& Cajal, Golgi and other scientists. Nowadays interpretations, followed by physiology ascension, regard synaptic and electrophysiological information as a consequence of the brain reactions in daily behavior situation with highly complex models. New perspectives of recently developed methods to investigate mind and behavior functions are increasingly reported by editorials in scientific journals. It is also a driver for scientists to merge their expertise in large scale multi-institutional network research projects. In fact, only multidisciplinary teams are able to face the key challenging questions emerging in the current neuroscientific perspective.

Relative to the context of the present work, this multidisciplinary scenario adds even more complexity to any attempt to use a structured project management risk evaluation method. An alternative look at the problem is to conceptualize the analysis in a portfolio of projects. Using this view, we may add value at the institutional level and be able to intermingle with financial disbursement and scientific results at different stages of the project. Thus, the complexities mentioned can be encapsulated and treated in a less detailed, but manageable, level of complexity.

Provided that concept, we aimed to develop a system to analyze return risk at diverse institutional levels. This can be applied at any organizational level of class hierarchy above a research laboratory. Relevant to the topic, we could take our country as an example. Brazil, at the date of this writing, occupies the 15th global position related to scientific paper production with 16,782 published manuscripts ${ }^{(7)}$. In order to translate this scientific achievement to technological development, a series of actions in the innovation process are required. And most importantly, these actions require scientific community participation in novel partnerships between public research institutions and private enterprises. In order to establish continuous scientific production, stakeholders external to the research institutions are required. An element to improve the understanding of the scientific process by both public and private stakeholders is needed. The innovation management in the research institutions should be committed with the new requirements and perspectives of each playing field. This commitment level is based on the assumption of clear understanding of the scientific process from all parts involved: we believe that our approach can also be useful in this context.

Science and technology policy studies have for many years accompanied the creation of new research centers all over the country and in several parts of the world. Strategic analysis of their structures and organizational competence was crucial to learn how to evaluate these research centers financially supported according to their guidance goals ${ }^{(6)}$. Competence mapping, methods, techniques and tools as institutional or company value resource are extremely significant for a country and the society - a phenomenon discussed by philosophers ${ }^{(8)}$.

For a fundamental research project examination two main issues are considered: the financial aspect and the research environment structure. The kind of outcome from each scientific project should be carefully planned and the funding should also follow some essential steps. The same ones considered for a common mutual fund shares investment. Risk analysis and the fund investment history are indispensable to guide a decision. Moreover, for a customer, potential donor or stakeholder involved in the budget approval is very important to feel satisfied not only with the project but the possible results and their impact in business or society. This impact perception must be clearly defined for each study and presented in a friendly language to reflect reliability. The suggested strategy evaluation on scientific investment return can also be part of science. A ranking of acceptable results for a specific research project and its complex variables could be better defined. The adequate limits included in an inspection process may be useful in the institutional routine. If the results of a project cross these earlier defined limits, the strategy policy may possibly become vulnerable. A strategy with a high level of susceptibility jeopardizes the expected outcomes. Certain sensible elements, with respect to research institutions appeal, comprise the policy ambiance, innovative process network, expertise fields and their consequences and new research application spots. These elements core may constitute a scientific and technologic network, integrating different qualified competences yielding more competitive atmosphere for room and resources seeking. Knowledge acquisition and technological assignment allied to human resource training and political capability is considered as an important strategic role in any research institute. 
Again, the need of an administrative tool applied to research programs or projects and their potential outcomes is crucial to succeed. Thus, new indexes or indicators are necessary to be developed to a research scope. There is no evidence of such index adopted in private or public research projects evaluation in spite of its risk factors and perspectives. The aim of the present study was to propose an expected risk measure of return index adapted to scientific projects. The proposed indicant addressed as RoSI (Return on Scientific Investment) is based on the ulcer index ${ }^{(9)}$ created to characterize the financial investment risk, a modeling tool based on variables that interact in semiquantitatively environments.

\section{OBJECTIVE}

To propose a measure (index) of expected risks to evaluate and follow up the performance analysis of research projects involving financial and adequate structure parameters for its development.

\section{METHODS}

\section{Ulcer index}

This index is a stock market risk measure devised by Peter Martin ${ }^{(9)}$, in 1987. It was established as a measure of volatility in downward direction (drawdowns) that occursina determined time or era. Theindexis based ona given past period of $N$ data and considers a stock price retracement level, expressed as a percentage

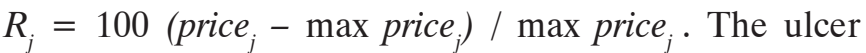
index is defined by the root mean square of these values expression $U I=\sqrt{\left(R_{1}^{2}+R_{2}^{2}+\ldots+R_{N}^{2}\right) / N}$. The calculation is robust for the sampling rate used and the percentage may be expressed as positive or negative values. This concept is showed in three profit curves strategies (Figure 2). The method presented herein measures scientific projects performance exploring distinct aspects or earlier established milestones. The main goal is to reach a pricing proceeding useful for scientific projects managing.

\section{Semi-quantitative computational modeling approach}

Artificial neural network applied to theory of variable interaction with animate causal diagrams. These diagrams are graphical tools that enable the visualization of causal relationships between all variables in a determined system. Moreover, this approach provides a systematic interpretation of a

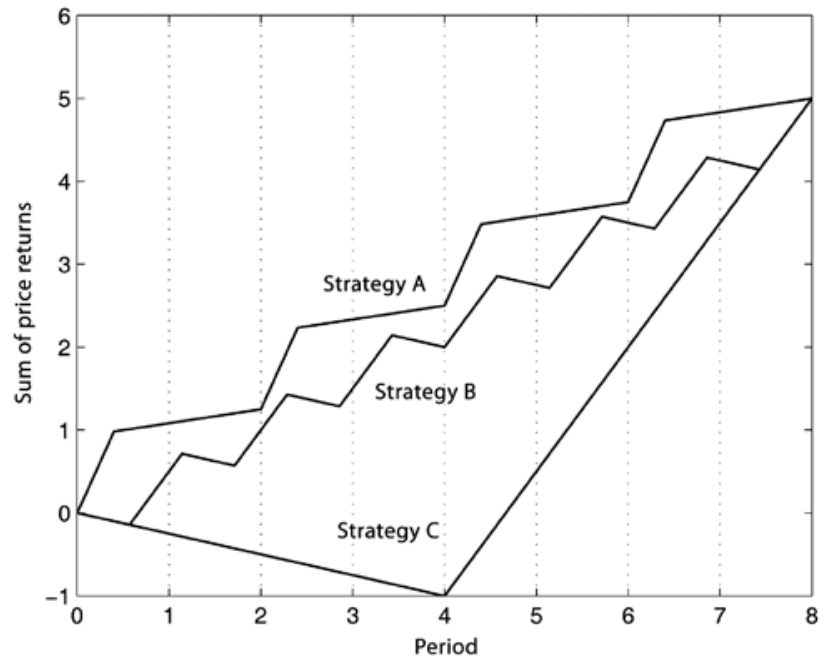

Figure 2. Three different strategies with the same final return, according to ulcer index definition $U I_{A}<U I_{B}<U I_{C}$

causal diagram and permits the creation of models regarding natural and human science. Distinct levels or states and rates or actions are considered to occur in a determined time-lapse. Despite constant values, both are necessary for the data representation and to integrate the results provide by the system. The variable quantification is calculated through the changing rate that alters a previous value level. On the other hand, levels are also defined by early effects accumulation and can be traced even in a non-activity scenario. Rather, the developed semi-quantitative model comprises the causal relationships through a specific topology in an artificial environment. This environment is considered as an interactive framework and will be available to be explored by its users. In this context, modeling seems to act as a managing process component. Therefore, the pricing of a project is a given variable originated from this semi-quantitative model (Figure 3). The

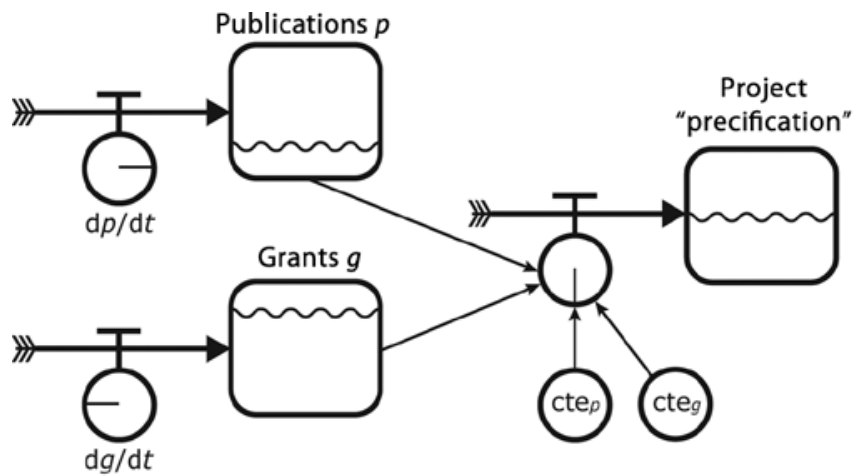

Figure 3. Depicts an example of project pricing model using the semiquantitative approach. The auxiliary variables suggested in this example are publications and grants; the output variable can be defined by a function of $p$ and $g$ weighted by the constants cte ${ }_{p}$ e cte $_{g}$ 
project pricing depends on diverse outcomes, such as publication quality, funding, patent registry and others. The modeling stands for project risk analysis simulation represented by possible risk variables characterized in an independent structure or network. Additionally, these project models may interact with other levels of the research grid where different projects are considered to have a common subject interface.

\section{Choosing variables criteria}

The definitions of the several variables to fulfill distinct levels of the semi-quantitative model are based on important concepts regarding transdisciplinarity. This concept comprehends a scientific approach for the creation of a knowledge unity. It articulates elements and diverse research groups beyond and between the disciplines and integrates new or revised perspectives into our ways of thinking. These variables comprise not only the professional or technical skills of a person, but include personnel character attributes as well as tacit knowledge compounds. Other set of variable types are related with established milestones involving crucial parts of a project to accomplish its objectives. Lastly, an acute interface among these defined levels and possible interactions between projects pertaining to different research groups are also considered by the system.

Our model was tested in three scientific projects on the topic of neuroimaging. The variables were defined according to the possible outcomes of the scientific findings. All projects have more than three years of development and were approved by the research project managing system of the Instituto Israelita de Ensino e Pesquisa Albert Einstein, São Paulo, Brazil. The main criteria considered herein for pricing were: grant income values, project expenses and published results.

\section{RESULTS}

The ulcer index was calculated for projects A, B and $\mathrm{C}$ at each semester. Different monthly curves reflected the ulcer indexes, identifying the project that may have a minor risk (project $\mathrm{C}$ ) related to development and expected results according to initial investment (Figure 4). The drawdown events shown in the curves occurred mainly when a large sum was made by the researcher with no concurrent outcome. On the other hand, when a paper was published, the project level drawdown decreases until a next predefined milestone. If the project goals were not achieved or a new expenditure

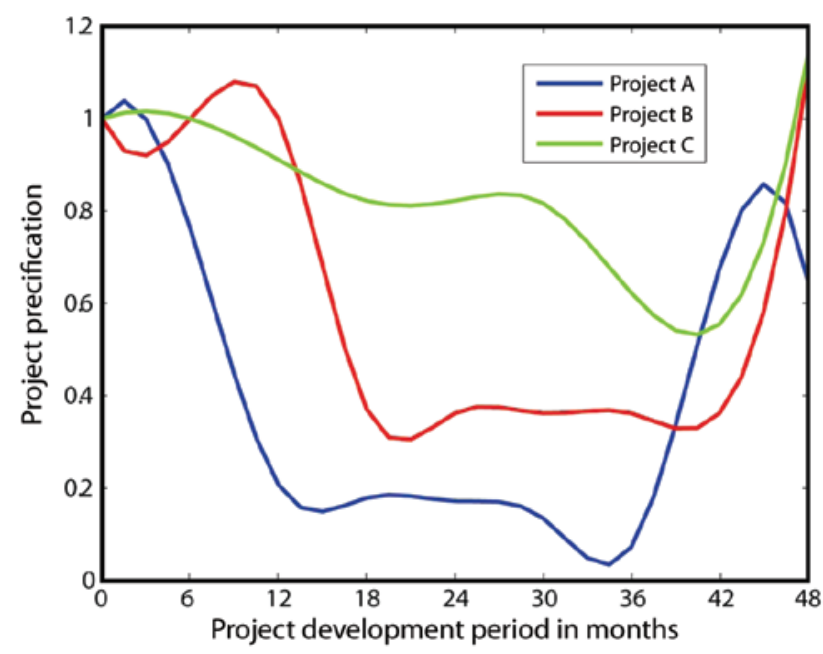

Figure 4. The graphic depicts three different curves that reflect the calculated ulcer index (UI) for projects A, B and C. According to the defined variable criteria, drawdowns represent an objective not achieved or an unjustified expenditure during the project development. The risk measures are $U I_{\mathrm{A}}=69.67, U I_{\mathrm{B}}=$ 50.29 and $U I_{C}=23.58$, respectively; thus the project $C$ has a minor risk when compared with $\mathrm{A}$ or $\mathrm{B}$

was made without proper justification, the model accommodates these variables providing a single index.

\section{DISCUSSION}

Here we propose a structured method resulting in a single index that conveys the notion of investment risk before a scientific project is executed or at any given time point during its execution. We showed the concept in real data from our institution, illustrating its application. In the following paragraphs we discuss the implications in an innovation scenario, bringing together science to technology development.

The gap between knowledge generation via scientific methods and productive sectors is a barrier for most societies, especially in developing countries. The current understanding of the integration between science and technology (innovation) is still in its birth in Brazil. Policy mechanisms designed to deal with general research contexts are very complex and bureaucratic, often halting translation to products that would benefit the society - and to a certain extent tend to block the ability to deal with the new findings ${ }^{(7)}$. In addition, technological innovations are powerful tools to attain goals in scientific project. Researchers will have a better chance to obtain funds for a project if they are able to convey the information needed to assess investment risks, enjoying opportunities and giving strength to promising solutions.

In a simple way, multicultural teams have to interact in order to make use of high level strategies 
to pioneer new business based on innovation. There is also a demand to create sustainability in accordance to a developed product or process. This product can be understood as an assembled object or intellectual product from the know-how resulting from a study. Innovation does not emerge automatically from a pure combination of strong $\mathrm{R} \& \mathrm{D}$; rather, there is a need to directly and mutually influence the innovation strategies ${ }^{(10)}$. Research centers, despite their scientific field of expertise, can not ignore the economic policies that organize trading transactions, including the model of competence management and the existence of a dynamic structure to deal with it.

Research management should not be considered as budget accountability or fault but as an extremely important investment that generates social benefits ${ }^{(7)}$. Technological foresight in this context is an important approach instrument for funding regarding science and technology fields, establishing research priorities to improve the insertion of research cores in innovation networks. By providing a direct and dynamic measurement, a foresight application directly returns real results closer to the expected social and economical revenue.

Management tools, such as RoSI, contribute to guarantee $\mathrm{R} \& \mathrm{D}$ activity competitiveness for a longterm period. In 1985, Coates defined the foresight as a process that has the objective of fully understanding the strength that depicts, in the long run, our future regulating policies, planning and decisionmaking dealings. This idea includes a qualitative and quantitative background to monitor signs and indicators related to development trends and their consequences. It provides the basis to prepare for future opportunities, organizing new projects or ideas that may stand at science borders. Technological foresight has an unquestionable dynamic reference because it emerged tuned to the evolutionary economics concepts from the 1980's. Foresight practice showed that technological and scientific advances depend on detailed planning and decisions made in the present. Success does not depend on inherent reasons or happens as an aleatory event ${ }^{(11)}$.

Our method is very useful as part of a system and practices for research management. Usually the board of directors in a research center consists of a heterogeneous scientific board of specialists designated from other research institutions and enterprises. Their missions include a macro-coordination proceeding associated to innovation, to facilitate communication involving stakeholders, to create and combine collective appointments and to arrange new networking partnerships ${ }^{(12)}$. The foresight is strongly suggested as a strategic practice to settle $R \& D$ priorities and support the efforts of science and technology for economic and social states requirements ${ }^{(13)}$. We believe that our structured risk analysis index is aligned to the need to future forecast. Nevertheless, the system requires contribution from researcher experts and stakeholders. If the parameters entered in the model are not mirrored by real context, the RoSI index will behave accordingly: it will not reflect the real outcomes.

It is important to notice that RoSI does not address the full innovation pipeline. Still, technological prospection is an analysis route of the possible challenges or future long term scenarios that embrace science and technology, economy and society. Identification of outcomes, evaluation of projects performance measures is essential to investigate areas, surfacing technologies with the purpose of creating benefits in a social and economical perspective. Despite the disputes related to science and technology expansion, there are other obstacles regarding external ambiance according to Morel: "science must not be considered as a subsystem that automatically defines patterns and general evolutionary guidelines, although it is submitted to extrinsic influences from its own fields of action"(14). Surely the meaning of an adequate environment to internally or externally innovate requires a system that should be based on both quantitative and qualitative information. Developed countries learned long ago that a rational innovation pipeline is decisive for boosting economical strength based on scientific and technological advances. In least-developed or developing countries, the absence of an innovation system impairs the community liaisons to guarantee science, technology and innovation. It jeopardizes the productive sector progress and as consequence their insertion in a global innovation platform ${ }^{(15)}$.

Another interesting contribution of structured risk is the catching-up process that occurs when developing countries take advantage at the moment of a worldwide technological transition. A real catching-up process may be reached through acquiring competences or capabilities that concur in technology creation and improvement, and it is considered a window of opportunity ${ }^{(16)}$. The technology course can be comprehended as an evolutionary direction of technological progress and observed primarily in the many extensions of the industrial sectors. Some important analytical structures should be considered 
on this spot: global technological and institutional ambiances, dynamic corporative learning process and technology transference ${ }^{(17)}$. Technological capability attainment is a complex learning procedure in all social orders. This course of action suffers the influence of the market economy, culture traditions, public policy, formal education and a state structure organization. A key point of the present work is the identification of project components that may contribute to the final result. These components are supposed to allow for adjustment or their roles in developing the original plan and afford more/less investment to achieve the desirable outcomes.

By employing computational algorithm to accomplish our objectives, we also had to combine two techniques. The index developed by Peter Martin was adopted because it presents the ability to explore different scenarios with the same return. Moreover, the modeling tool proposed in this framework does not require mathematic or programming skills to be operated. The user may only introduce relevant variables to the system and point out their interactions as causalities or variances. In other words, the user would work with previous defined parameters for acquiring knowledge related to a specific content ${ }^{(18)}$.

To present and discuss institutional characteristics regarding innovation technology standpoints is very important to understand the elements within the available research structure. The relation amid different agents of the innovation system with the productive segment and society, represents critical aspects of these central elements to be administered. This relation maintains international notability positions in the global technological scenario, beyond an augmented technological production and innovation process. It also has the potential to improve communication and reciprocal assistance between the research teams, handling in an organized manner all questions arising from the necessary interactions. Thus, we may suggest RoSI as one of the indexes directly applied to processes that certainly helps fostering science and technology development.

Financial support to scientific activity started in private held companies is a reality in our country, but still immature. Shareholders (individual or corporate personhood) need to share a common view of the scientific process. A pragmatic view at research results is paramount to plan choices and new paths to innovation. Notwithstanding the scientific area explored by scientists or researchers, there is not a delineated pipeline to be followed or guidance for managing investments in a multicultural environment.

In our experience this is the first qualitative strategy with a quantitative bias in the evaluation of the chances of success and investment adequacy associated to research risks.

\section{CONCLUSION}

Herewith provided a tool applicable to risk concept involving specific variables and scenarios that refers to a factual assumption. The RoSI index supports decision-making processes of the projects searching for sustainability and management mechanisms integrated with the academic and scientific areas.

\section{REFERENCES}

1. Kline S, Rosenberg N. An overview of innovation. In: Landau R, Rosenberg N. The positive sum strategy. Washington (DC): National Academy of Press; 1986. p.275-306.

2. Barré R, Papon P. Economie et politique de la science et de la technologie. Paris: Pluriel; 1993. (Hachette-Collection)

3. Schon D. Technology and change; The new heraclites. New York (NY): Delacorte Press; 1967.

4. Arthur WB. Competing technologies, increasing returns, and lock-in by historical events. Econ J. 1987:99(394):116-31.

5. Freeman $\mathrm{C}$. The economics of industrial innovation. Harmondsworth: Penguin Books; 1974.

6. Brandão HP, Guimarães TA.Gestão de competências e gestão de desempenho: tecnologias distintas ou instrumentos de um mesmo constructo? Rev Adm Emp. 2001;41(1):8-15.

7. Salles-Filho S. Ciência, tecnologia e inovação: a reorganização da pesquisa pública no Brasil. Campinas (SP): Komedi; 2000.

8. Vogt C. Cultura científica: desafios. São Paulo: Editora da Universidade de São Paulo; 2006.

9. Martin P, McCann B. The investors guide to fidelity funds. New Jersey: John Wiley \& Sons; 1989.

10. Quadros R. A combinação de marketing e P\&D é importante para o processo de inovação: inovação é invenção que chega ao mercado. Campinas (SP): Universidade Estadual de Campinas; 2004.

11. Coates J. Foresight in federal government policy making. Fut Res Ouart. 1985;1:29-53.

12. Grupp $H$, Linstone HA. National technology foresight activities around the globe: resurrection and new paradigms. Technol Forecast Soc Change. 1999; 60(1): 85-94

13. Martin BR, Johnston R. Technology foresight for wiring up the National Innovation System: experiences in Britain, Australia and New Zealand. Technol Forecast Soc Change.1999; 60(1):37-54.

14. Morel RL. Ciência e estado: a política científica no Brasil. São Paulo: TA Queiroz; 1979.

15. Herrera AO. Los determinantes sociales de la política científica en América Latina. Política científica explícita y política científica implícita. Redes. 1995; 2(5):117-31.

16. Perez $C$, Soete L. Catching up in technology: entry barriers and windows of opportunity. In: Dosi G, Freeman C, Nelson R, Silverberg G, Soete L, editors. Technical change and economic theory. London: Pinter; 1988. p.458-79. 
17. Kim L. Pros and cons of internacional technology transfer: a developing country view. In: Agmon T, Glinoweds MA, editors. Technology transfer in international business. New York: Oxford; 1991. p.2-26.
18. Mandinac EB, Cline HF. Classroom dynamics: implementing a technologybased learning environment. Hillsdale(NJ): Lawrence Erlbaum Associates; 1994. 